Marquette University

e-Publications@Marquette

Exercise Science Faculty Research and

Publications

Exercise Science, Department of

3-2014

\title{
Effect of Fontan Fenestration on Regional Venous Oxygen Saturation During Exercise: Further Insights Into Fontan Fenestration Closure
}

\author{
Rohit S. Loomba \\ Medical College of Wisconsin \\ Michael E. Danduran \\ Marquette University, michael.danduran@marquette.edu \\ Jennifer E. Dixon \\ Children's Hospital of Wisconsin \\ Rohit P. Rao \\ Phoenix Children's Hospital
}

Follow this and additional works at: https://epublications.marquette.edu/exsci_fac

Part of the Cardiology Commons, and the Exercise Science Commons

\section{Recommended Citation}

Loomba, Rohit S.; Danduran, Michael E.; Dixon, Jennifer E.; and Rao, Rohit P., "Effect of Fontan Fenestration on Regional Venous Oxygen Saturation During Exercise: Further Insights Into Fontan Fenestration Closure" (2014). Exercise Science Faculty Research and Publications. 57.

https://epublications.marquette.edu/exsci_fac/57 
Marquette University

e-Publications@Marquette

\section{Exercise Sciences Faculty Research and Publications/College of Health} Sciences

This paper is NOT THE PUBLISHED VERSION; but the author's final, peer-reviewed manuscript. The published version may be accessed by following the link in the citation below.

Pediatric Cardiology, Vol. 35 (2014): 514-520. DOI. This article is (C) Springer and permission has been granted for this version to appear in e-Publications@Marquette. Springer does not grant permission for this article to be further copied/distributed or hosted elsewhere without the express permission from Springer.

\section{Effect of Fontan Fenestration on Regional Venous Oxygen Saturation During Exercise: Further Insights into Fontan Fenestration Closure}

Rohit S. Loomba

Department of Cardiology, Children's Hospital of Wisconsin, Milwaukee, WI Michael E. Danduran

Department of Cardiology, Children's Hospital of Wisconsin, Milwaukee, WI Jennifer E. Dixon

Department of Cardiology, Children's Hospital of Wisconsin, Milwaukee, WI Rohit P. Rao

Department of Cardiology, Phoenix Children's Hospital, Phoenix, AZ 


\section{Abstract}

Fontan fenestration closure is a topic of great debate. The body of data regarding the risks and benefits of fenestration closure is limited yet growing. Previous studies have demonstrated that Fontan patients have less exercise capacity than those with normal cardiovascular anatomy. Differences also have been noted within various subgroups of Fontan patients such as whether Fontan is fenestrated or not. This study aimed to compare trends in regional oxygen saturations using near-infrared spectroscopy (NIRS) in patients with Fontan circulations during ramping exercise to further delineate differences between patients with and without a fenestration. It was hypothesized that Fontan patients with fenestrations have better exercise times, higher absolute regional oxygen venous saturations, and smaller arteriovenous differences than Fontan patients without fenestrations. For this study, 50 consecutive Fontan patients and 51 consecutive patients with normal cardiovascular anatomy were recruited. Placement of NIRS probes was performed to obtain regional oxygen saturations from the brain and the kidney. Readings were obtained at 1-min intervals during rest, exercise, and recovery. A standard Bruce protocol was used with a 5-min recovery period. Absolute regional tissue oxygenation values $\left(\mathrm{rSO}_{2}\right)$ and arterial-venous oxygen saturation differences $\left(\mathrm{AVDO}_{2}\right)$ calculated as arterial oxygen saturation $\left(\mathrm{SPO}_{2}\right)-\mathrm{rSO}_{2}$ for normal versus Fontan patients and for fenestrated versus unfenestrated Fontan patients were compared using independent $t$ tests. When normal and Fontan patients were compared, the Fontan patients had a significantly shorter duration of exercise (9.3 vs $13.2 \mathrm{~min} ; p<0.001$ ). No statistically significant difference in $\mathrm{rSO}_{2}$ change or $\mathrm{AVDO}_{2}$ was evident at the time of peak exercise, at 2 min into the recovery, or at 5 min into the recovery. A small oxygen debt also was paid back to the brain in the Fontan patients after exercise, as evidenced by a narrower $\mathrm{AVDO}_{2}$ than at baseline. The comparison of Fontan patients with and without fenestration showed no statistically significant difference in exercise time, $\mathrm{rSO}_{2}$ change, or $\mathrm{AVDO}_{2}$. The Fontan patients were noted to have shorter exercise times than the normal patients and also appeared to have an alteration in postexertional regional blood flow. However, when the various Fontan subtypes were compared by presence or absence of a fenestration, no significant differences were noted with regard to change in regional oxygen saturation or arteriovenous oxygen saturation. Thus, for patients with Fontan physiology, closure of the fenestration does not seem to have an impact on the dynamics of regional oxygen extraction during exercise or recovery.

\section{Introduction}

Findings have well documented that the Fontan procedure used as palliation for patients with a single ventricle leads to a reduction in exercise capacity. This manifests itself through a significant reduction in exercise time, peak oxygen consumption (peak $\mathrm{VO}_{2}$ ), and exercise intensity $[5,8,10,11,13,14,16,18,22,26,32,35,36,38]$. This impairment in exercise capacity results from the interaction of many different factors, which include, but are not limited to, the following: a dramatic increase in pulmonary artery systolic pressure with subsequent reduction in ventricular stroke volume, a decrease in ventricular end-diastolic pressure, inadequate ventricular preoload reserve, impairment of the autoregulation of systemic vascular resistance, and the absence of a prepulmonary pump $[2,4,12,20,21,27,33,34]$. Exercise capacity is of particular importance in Fontan patients because it affects quality of life in this physiologically unique population.

During the years since the initial reports of the Fontan operation, this palliative procedure has undergone many modifications and has seen new applications. One such modification has been the introduction of a fenestration. The short-term benefits of fenestration include a shorter postoperative hospital stay, decreased chest tube drainage, and a decreased need for mechanical ventilation $[1,6,7]$. However, the long-term effects of fenestration are unclear.

The potential benefits of fenestration beyond the early postoperative period include reduction of protein-losing enteropathy, plastic bronchitis, and dysrhythmias. The potential risks of fenestration include cyanosis and 
thromboembolism. The current data on the impact of fenestration on exercise capacity is similarly conflicting, with no obvious answer as to whether a benefit exists or not [24, 25].

Previous studies have demonstrated regional tissue oxygenation $\left(\mathrm{rSO}_{2}\right)$ trends in Fontan patients using nearinfrared spectroscopy (NIRS) during cardiopulmonary exercise testing (CPET) [9, 30, 31]. The NIRS techniques use the Beer-Lambert law in measuring the concentration of a substance using its absorption of light [29]. The NIRS procedure allows for a noninvasive, continuous means of monitoring $\mathrm{rSO}_{2}$ by detecting venous-weighted oxyhemoglobin saturation in real time.

This study aimed to investigate further the effect of fenestration status on exercise capacity using $\mathrm{rSO}_{2}$ while also characterizing NIRS trends in exercising Fontan patients with varying fenestration statuses.

\section{Methods}

This study was initiated with funding assistance from the Children's Research Institute, a division of Children's Hospital and Health System, and the Medical College of Wisconsin, Milwaukee, Wisconsin. It received approval from the Institutional Review Board. All patients who had undergone a previous Fontan procedure were eligible for inclusion in the study if they had been referred to undergo CPET by a cardiologist at the Herma Heart Center's Exercise Physiology Laboratory for further evaluation of symptoms or function. Patients with no structural heart disease or acquired heart disease who had been referred for CPET also were eligible for inclusion and formed the control group.

The single-ventricle patients included in the study all had undergone a three-stage approach for palliation consisting of a Norwood procedure, Glenn anastomosis, and completion Fontan. All the patients underwent a routine clinical evaluation consisting of a thorough history and physical examination before CPET. Consent and assent from the parents were obtained before enrollment of any patients in the study. All patients were tested during an outpatient visit, and no activity restrictions were given before testing.

\section{Preexercise Testing}

The CPET protocol began with application of 12-lead electrocardiogram leads, an automated oscillometric blood pressure cuff on the left arm, and a pulse oximeter on the right index finger to measure arterial oxygen saturation $\left(\mathrm{SpO}_{2}\right)$ (GE-Marquette, Waukesha, WI, USA). Four NIRS probes with 4-cm source-detector spacing and shallow-field rejection (Adult Somasensor, Covidien 5100C; Somanetics Corp, Troy, MI, USA) were placed on the forehead midline $\left(\mathrm{rSO}_{2} \mathrm{C}\right)$, below the 12th rib in the left paravertebral space $\left(\mathrm{rSO}_{2} \mathrm{R}\right)$, on the vastus lateralis $\left(\mathrm{rSO}_{2} \mathrm{~L}\right)$, and on the deltoid muscle $\left(\mathrm{rSO}_{2} \mathrm{~A}\right)$, respectively. Resting echocardiography (Siemens; Acuson, Mountain View, CA, USA) and electrocardiography (GE Medical Systems; Milwaukee, WI, USA) were performed before CPET.

Four-site regional $\mathrm{rSO}_{2}$ and $\mathrm{SpO}_{2}$ were measured and recorded continuously at 6-s intervals during rest, exercise, and a 5-min recovery period. Baseline spirometry (Care Fusion, Yorba Linda, CA, USA) was performed using a forced expiratory maneuver according to the standards of the American Thoracic Society. Forced vital capacity (FVC), forced expiratory volume in $1 \mathrm{~s}\left(\mathrm{FEV}_{1}\right)$, peak expiratory flow (PEF), and maximal mid-expiratory flow were collected. Measurements of breath-by-breath oxygen consumption $\left(\mathrm{VO}_{2}\right)$, carbon dioxide production $\left(\mathrm{VCO}_{2}\right)$, and instantaneous respiratory quotient $(\mathrm{RQ})$ also were obtained.

\section{Exercise Testing}

Patients were oriented to the treadmill and given specific instructions about what to expect during the exercise portion of the study. After 1 min of baseline data collection, a modified Bruce protocol was initiated. The workload was progressively increased at set intervals throughout the test until the patient reached voluntary or symptom-limited exhaustion (quitting time [QT]). 
Electrocardiography, blood pressure, oxygen saturation, and breath-by-breath ventilatory data were recorded at 1-min intervals throughout the exercise portion of the test. Immediately after the exercise portion of the test was a 5 -min recovery period ( $3 \mathrm{~min}$ of walking followed by a $2 \mathrm{~min}$ of sitting). All $\mathrm{SpO}_{2}$, heart rate, blood pressure, $\mathrm{VO}_{2}, \mathrm{VCO}_{2}, \mathrm{RQ}$, and NIRS data were synchronously aggregated. Patients unable to complete the CPET protocol and those who had incomplete metabolic chart data acquisition were excluded from the study.

\section{Data Analysis}

Means and standard deviations were calculated for all baseline characteristics and then compared between the control and Fontan patients and between the fenestrated and unfenestrated Fontan patients using unpaired $t$ tests. The mean percentage of change in $\mathrm{rSO}_{2}$ and rterial-venous oxygen saturation differences $\left(A V D O_{2}\right)$ from baseline to the following time points was calculated and plotted: peak exercise, 2 min after exercise, and $5 \mathrm{~min}$ after exercise. The mean change at these time points for the normal and Fontan groups then was compared using the unpaired $t$ test. Statistical analysis was performed using SPSS statistical software, version 20.0 (SPSS, Chicago, IL, USA). All $p$ values lower than 0.05 were considered statistically significant.

\section{Results}

\section{Normal Versus Fontan Patients}

The study enrolled 51 normal patients and 50 Fontan patients. Comparisons of the baseline characteristics between these two groups are summarized in Table 1. As expected, the Fontan patients tended to be younger and to have lower weight (in pounds), FVC, $\mathrm{FEV}_{1}$, resting systolic blood pressure, and resting diastolic blood pressure. The Fontan patients also tended to have significantly lower resting renal oxygen saturations (65.4 \pm 10.8 vs $76.8 \pm 9.3 \% ; p<0.001)$ and lower cerebral oxygen saturations $(60.7 \pm 8.8$ vs $69.9 \pm 10.1 \% ; p<0.001)$. When this relationship was further examined in terms of Fontan fenestration status, the unfenestrated Fontan patients had a lower mean resting cerebral saturation $(63.1 \pm 8.6 \%)$ than the normal patients $(p=0.002)$ as well as a lower mean resting renal saturation $(66.8 \pm 11.0 \% ; p<0.001)$.

Table 1 Comparison of baseline characteristics between normal and Fontan patients

\begin{tabular}{|l|l|l|l|}
\hline & Normal & Fontan & $p$ Value \\
\hline No. of patients & 51 & 50 & \\
\hline No. of males: $n(\%)$ & $26(52)$ & $33(66)$ & \\
\hline Age (years) & $16.6 \pm 6.7$ & $11.6 \pm 3.8$ & $<0.001$ \\
\hline Weight (Ib) & $132.8 \pm 34.2$ & $79.4 \pm 28.5$ & $<0.001$ \\
\hline Height (in.) & $65.9 \pm 4.9$ & $59.8 \pm 17.1$ & 0.012 \\
\hline FVC (L) & $3.8 \pm 1.0$ & $1.9 \pm 0.8$ & $<0.001$ \\
\hline FEV ${ }_{1}(\mathrm{~L})$ & $3.4 \pm 0.9$ & $1.6 \pm 0.6$ & $<0.001$ \\
\hline PEF (L/min) & $6.8 \pm 1.7$ & $7.3 \pm 13.5$ & 0.895 \\
\hline Resting respiratory rate (rpm) & $49.7 \pm 11.6$ & $51.0 \pm 12.3$ & 0.626 \\
\hline Resting heart rate (bpm) & $74.5 \pm 12.5$ & $83.3 \pm 16.8$ & $<0.001$ \\
\hline Resting systolic blood pressure (mmHg) & $110.7 \pm 8.5$ & $100.5 \pm 11.1$ & $<0.001$ \\
\hline Resting diastolic blood pressure (mmHg) & $68.0 \pm 8.3$ & $60.2 \pm 8.3$ & $<0.001$ \\
\hline Resting systemic saturation (\%) & $95.0 \pm 1.0$ & $93.1 \pm 4.1$ & 0.002 \\
\hline Resting renal saturation (\%) & $76.8 \pm 9.3$ & $65.4 \pm 10.8$ & $<0.001$ \\
\hline Resting cerebral saturation (\%) & $69.9 \pm 10.1$ & $60.7 \pm 8.8$ & $<0.001$ \\
\hline Resting deltoid saturation (\%) & $76.8 \pm 9.0$ & $70.4 \pm 7.6$ & \\
\hline Resting vastus lateralis saturation (\%) & $62.9 \pm 11.1$ & $56.6 \pm 8.2$ & 0.009 \\
\hline Exercise time (min) & $13.2 \pm 2.5$ & $9.3 \pm 1.8$ & $<0.001$ \\
\hline VO ${ }_{2}$ at peak exercise & $2.6 \pm 0.9$ & $1.4 \pm 0.5$ & 0.254 \\
\hline
\end{tabular}




\begin{tabular}{|l|l|l|l|}
\hline End-tidal $\mathrm{CO}_{2}$ at peak exercise & $37.7 \pm 5.0$ & $31.5 \pm 4.9$ & 0.283 \\
\hline $\mathrm{RQ}$ at peak exercise & $1.1 \pm 0.1$ & $1.0 \pm 0.9$ & 0.675 \\
\hline
\end{tabular}

$F V C$ forced vital capacity, $F E V_{1}$ forced expiratory volume in $1 \mathrm{~s}, P E F$ peak expiratory flow, $r p m$ revolutions/min, bpm beats/min, $V_{O_{2}}$ oxygen consumption, $\mathrm{CO}_{2}$ carbon dioxide, $R Q$ respiratory quotient

The fenestrated Fontan patients had a lower mean resting cerebral oxygen saturation $(55.7 \pm 7.3 \% ; p<0.001)$ than the normal patients and a lower mean resting renal oxygen saturation $(58.3 \pm 18.5 \% ; p<0.001)$. Exercise time in minutes also was significantly shorter among the Fontan patients than among the normal patients $(9.3 \pm 1.8 \%$ vs $13.2 \pm 2.5 \% ; p<0.001)$.

Regional renal oxygen saturations showed a greater change from baseline in the Fontan patients than in the normal patients ( -4.1 vs $-0.6 \%) 2$ min into the recovery period. Otherwise, renal $\mathrm{rSO}_{2}$ did not differ significantly at peak exercise or $5 \mathrm{~min}$ into recovery. The change in cerebral $\mathrm{rSO}_{2}$ from baseline to any time point did not differ significantly between the Fontan and normal patients (Table 2). Neither did the renal or cerebral $\mathrm{AVDO}_{2}$ differ significantly at the predefined time points between the Fontan and normal patients. A morphologic right ventricle was found in $\mathbf{2 7}$ of the Fontan patients and a morphologic left ventricle in the remaining patients.

Table 2 Change in regional venous oxygen saturations between normal and Fontan patients at predefined times $^{\mathrm{a}}$

\begin{tabular}{|l|l|l|l|}
\hline & $\begin{array}{l}\text { Change from rest to } \\
\text { peak exercise }\end{array}$ & $\begin{array}{l}\text { Change from rest to } 2 \mathrm{~min} \\
\text { into recovery }\end{array}$ & $\begin{array}{l}\text { Change from rest to 5 min } \\
\text { into recovery }\end{array}$ \\
\hline Kidney: normal & $-18.5(-24.1)$ & $-0.5(-0.6)^{\mathrm{b}}$ & $1.4(1.8)$ \\
\hline Kidney: Fontan & $-14.9(-22.8)$ & $-2.7(-4.1)$ & $-0.3(-0.4)$ \\
\hline Brain: normal & $-5.5(-7.6)^{\mathrm{b}}$ & $0.1(0.1)$ & $3.9(5.6)$ \\
\hline Brain: Fontan & $-7.0(-11.5)$ & $0.7(1.2)$ & $4.1(6.7)$ \\
\hline Deltoid: normal & $20.2(-26.3)$ & $2.8(-3.7)$ & $1.5(2.0)$ \\
\hline Deltoid: Fontan & $-14.5(-20.6)$ & $-4.6(-6.6)$ & $-0.9(-1.3)$ \\
\hline $\begin{array}{l}\text { Vastus lateralis: } \\
\text { normal }\end{array}$ & $-8.3(-13.2)$ & $8.7(13.8)^{\mathrm{b}}$ & $9.8(15.6)$ \\
\hline $\begin{array}{l}\text { Vastus lateralis: } \\
\text { Fontan }\end{array}$ & $-6.0(-10.6)$ & $3.6(6.3)$ & $4.6(8.1)$ \\
\hline
\end{tabular}

${ }^{a}$ Values are expressed as absolute change (\% change)

${ }^{b}$ Significant difference in $\mathrm{rSO} 2$ between the NL and Fontan groups at any given time interval

\section{Fenestrated Versus Unfenestrated Fontan}

Of the 50 Fontan patients, 16 were fenestrated and 34 were unfenestrated. The baseline characteristics of these two groups demonstrated significantly lower age, weight, and height in the fenestrated Fontan group (Table 3). The baseline FVC, FEV 1 , resting systolic blood pressure, and resting diastolic blood pressure also were significantly lower in this group. The resting systemic oxygen saturations were significantly lower in the fenestrated Fontan patients, with an average saturation of $89.3 \%$ compared with $94.9 \%$ in the unfenestrated Fontan patients $(p<0.001)$. The resting cerebral venous oxygen saturations also were lower in the fenestrated Fontan patients, with an average saturation of $55.7 \%$ compared with $63.1 \%$ in the unfenestrated Fontan patients $(p<0.003)$. The exercise times did not differ significantly between the two groups, with the fenestrated Fontan patients averaging 8.7 min compared with 9.6 min among the unfenestrated Fontan patients.

Table 3 Comparison of baseline characteristics between Fontan patients with and without fenestration Fenestrated $\quad$ Unfenestrated $p$ value 


\begin{tabular}{|l|l|l|l|}
\hline No. of patients & 16 & 34 & \\
\hline No. of males: $n(\%)$ & $9(56)$ & $24(71)$ & \\
\hline Age (years) & $8.8 \pm 2.1$ & $12.9 \pm 4.3$ & $<0.001$ \\
\hline Weight (Ib) & $57.7 \pm 14.3$ & $89.0 \pm 28.3$ & $<0.001$ \\
\hline Height (in.) & $50.3 \pm 5.5$ & $64.1 \pm 19.0$ & $<0.001$ \\
\hline FVC (L) & $1.3 \pm 0.2$ & $2.3 \pm 0.8$ & 0.002 \\
\hline FEV $($ (L) & $1.2 \pm 02$ & $1.9 \pm 0.6$ & 0.006 \\
\hline PEF (L/min) & $3.2 \pm 0.9$ & $4.5 \pm 19.1$ & 0.110 \\
\hline Resting respiratory rate (rpm) & $59.1 \pm 9.7$ & $48.9 \pm 12.3$ & 0.049 \\
\hline Resting heart rate (bpm) & $86.4 \pm 18.5$ & $81.9 \pm 16.1$ & 0.422 \\
\hline Resting systolic blood pressure $(\mathrm{mmHg})$ & $93.8 \pm 8.3$ & $103.7 \pm 1.1 .1$ & 0.001 \\
\hline Resting diastolic blood pressure $(\mathrm{mmHg})$ & $53.5 \pm 6.8$ & $63.4 \pm 7.1$ & $<0.001$ \\
\hline Resting systemic saturation (\%) & $89.3 \pm 4.1$ & $94.9 \pm 2.8$ & $<0.001$ \\
\hline Resting renal saturation (\%) & $62.2 \pm 10.4$ & $66.8 \pm 11.0$ & 0.172 \\
\hline Resting cerebral saturation (\%) & $55.7 \pm 7.3$ & $63.1 \pm 8.6$ & 0.003 \\
\hline Resting deltoid saturation (\%) & $65.6 \pm 5.7$ & $72.4 \pm 7.9$ & 0.075 \\
\hline Resting vastus lateralis saturation (\%) & $56.8 \pm 9.6$ & $56.5 \pm 8.4$ & 0.954 \\
\hline Exercise time (min) & $8.7 \pm 1.6$ & $9.6 \pm 1.8$ & 0.089 \\
\hline VO ${ }_{2}$ at peak exercise & $0.9 \pm 0.2$ & $1.5 \pm 0.4$ & 0.438 \\
\hline End-tidal CO ${ }_{2}$ at peak exercise & $28.9 \pm 3.9$ & $32.2 \pm 4.9$ & 0.284 \\
\hline RQ at peak exercise & $0.9 \pm 0.1$ & $1.0 \pm 0.1$ & 0.734 \\
\hline
\end{tabular}

$F V C$ forced vital capacity, $F E V_{1}$ forced expiratory volume in $1 \mathrm{~s}, P E F$ peak expiratory flow, $r p m$ revolutions/min, $b p m$ beats/min, $V \mathrm{O}_{2}$ oxygen consumption, $\mathrm{CO}_{2}$ carbon dioxide, $R Q$ respiratory quotient

The change in renal and cerebral $\mathrm{rSO}_{2}$ from baseline to predefined time points is depicted in Table 4. This change from baseline to any of the predefined time points did not differ between the Fontan patients based on fenestration status. The only exception to this was observed 5 min into the recovery, at which point the unfenestrated Fontan patients had a 1.2-point increase in renal venous oxygen saturation from resting values compared with a 5.9-point decrease in the fenestrated group. Table 3 compares the average renal and cerebral $\mathrm{rSO}_{2}$ trends during CPET between the fenestrated and unfenestrated Fontan patients. The $\mathrm{AVDO}_{2}$ did not differ between these two groups at any of the predefined time points.

Table 4 Change in regional venous saturations between Fontan patients with and without fenestration at predefined times

\begin{tabular}{|l|l|l|l|}
\hline & $\begin{array}{l}\text { Change from rest } \\
\text { to peak }\end{array}$ & $\begin{array}{l}\text { Change from rest to } 2 \text { min } \\
\text { into recovery }\end{array}$ & $\begin{array}{l}\text { Change from rest to } 5 \text { min } \\
\text { into recovery }\end{array}$ \\
\hline Kidney: fenestrated & $-14.4(-23.1)$ & $-0.4(-5.9)$ & $-3.7(-5.9)^{\mathrm{b}}$ \\
\hline Kidney: unfenestrated & $-14.7(-22.0)$ & $-2.3(-3.5)$ & $0.8(1.2)$ \\
\hline Brain: fenestrated & $-5.1(-9.1)$ & $1.2(2.1)$ & $4.5(8.1)$ \\
\hline Brain: unfenestrated & $-7.6(-12.1)$ & $0.4(0.7)$ & $3.8(6.1)$ \\
\hline Deltoid: fenestrated & $-3.2(-4.9)^{\mathrm{b}}$ & $-3.4(-5.2)$ & $-3.8(-5.8)$ \\
\hline Deltoid: unfenestrated & $-16.4(-22.6)$ & $-5.2(-7.2)$ & $0.7(1.0)$ \\
\hline $\begin{array}{l}\text { Vastus lateralis: } \\
\text { fenestrated }\end{array}$ & $-2.0(-3.5)$ & $0.7(1.2)$ & $0.1(0.2)^{\mathrm{b}}$ \\
\hline
\end{tabular}




\begin{tabular}{|l|l|l|l|}
\hline $\begin{array}{l}\text { Vastus lateralis: } \\
\text { unfenestrated }\end{array}$ & $-5.3(-9.3)$ & $4.4(7.7)$ & $6.8(12.02)$ \\
\hline
\end{tabular}

avalues are expressed as absolute change (\% change)

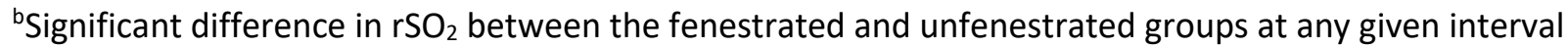

In terms of peak $\mathrm{VO}_{2}$, the Fontan patients with fenestration had a mean of $33.0 \mathrm{~mL} / \mathrm{kg} / \mathrm{min}$ compared with Fontan patients without fenestration, who had a mean of $34.6 \mathrm{~mL} / \mathrm{kg} / \mathrm{min}$. When these are converted into percentage of predicted values, the Fontan patients with fenestration had a mean of $72.1 \pm 7.5 \%$ compared with a mean of $72.3 \pm 13.3 \%$ for the Fontan patients without fenestration. Neither of these comparisons demonstrated any statistical difference, with $p$ values of 0.633 and 0.977 , respectively.

\section{Discussion}

This study is the first to report the use of NIRS during CPET in Fontan patients. The findings demonstrate no significant effect of fenestration status on regional venous oxygen saturations during exercise in Fontan patients in different visceral beds with differing flow metabolism control mechanisms. Changes in cerebral, renal, and skeletal muscle NIRS values from baseline to various points in CPET did not differ significantly between the two groups except for minor differences noted at the 5-min recovery time point in cerebral venous oxygen saturations. The $\mathrm{AVDO}_{2}$ also did not differ between the two groups, demonstrating that distribution of blood flow and oxygen extraction during exercise may be unaffected by fenestration status. These trends were noted despite the lower absolute regional oxygen saturations noted in the fenestrated group, a phenomenon expected because of the right-to-left shunt provided by the fenestration.

Together with similar NIRS trends, both the Fontan patients with and without fenestration also had similar exercise times in this cohort. This, however, may simply represent the findings for a relatively younger Fontan population. Previous studies have documented that Fontan patients in late adolescence tend to have the greatest decrease in exercise capacity, so it still is possible that fenestration status has effects on exercise time that are statistically significant as Fontan patients age $[15,17]$. Exercise times in Fontan patients have not been reported previously with respect to fenestration status specifically.

Regarding ventilatory capacity, this study found no difference in absolute peak $\mathrm{VO}_{2}$ or percentage of predicted peak $\mathrm{VO}_{2}$ between the Fontan patients with and without fenestration. This indicates that exercise capacity may not differ between Fontan patients based on fenestration status. This finding is consistent with the findings of an earlier study by Meadows et al. [24], which demonstrated no improvement in peak $\mathrm{VO}_{2}$ in patients before and after fenestration closure. The study by Meadows et al. [24], however, did find improvements in the $\mathrm{VE} / \mathrm{VCO}_{2}$ slope, end-tidal $\mathrm{CO}_{2}$ at the anaerobic threshold, and end-tidal $\mathrm{O}_{2}$ at peak exercise.

An additional finding of note was the greater $\mathrm{AVDO}_{2}$ observed in the Fontan patients than in the normal patients. Although this was not surprising in and of itself, the fact that this occurred even when fenestrated and unfenestrated Fontan patients were compared with normal patients separately is surprising. This may have been due in part to a limitation in cerebral blood flow resulting from the lack of a subpulmonary ventricle and from the subsequent low systemic venous compliance. An exaggerated hyperventilatory response in Fontan patients during exercise also may contribute to this [30].

Data on significant differences between Fontan patients with and without fenestration can help to determine whether fenestration closure is necessary or not. Currently, no guidelines on fenestration closure exist, and the decision often is based on physician preference and limited anecdotal evidence. Whether a fenestration offers a benefit in the long term or not still remains to be well delineated. 
A study by Ono et al. [28] demonstrated that those with a fenestration had statistically significantly longer survival and freedom from tachyarrhythmia 10 years after the Fontan procedure than those without a fenestration. Freedom from reoperation at 10 years also was greater, although this difference did not reach statistical significance.

The benefits of a fenestration in reducing the incidence of protein-losing enteropathy also have been demonstrated. One such study evaluated patients who underwent transcatheter Fontan fenestration for protein-losing enteropathy after a median of 11.3 years, with limited success in preventing future recurrences. Many of the recurrences reported occurred years after the fenestration, a point at which the fenestration may have spontaneously closed. Thus, a patent fenestration may have provided some benefit for these patients even long after the Fontan procedure [37].

The benefits of fenestration closure also have been documented. In addition to improvement in arterial oxygen saturations, improvements in aerobic capacity also have been noted [23].

Another series followed patients for 10 years after the Fontan procedure and noted improvement in oxygenation, reduction in the need for cardiac medications, and improvement in somatic growth. It also has been hypothesized that fenestration closure may reduce the risk for thromboembolic events, although this has not been substantiated by studies $[3,19]$.

The limitations of this study included susceptibility to bias due to its retrospective nature. Fenestrations are more common in the more recent surgical era, and this may be reason why those with fenestration had a lower baseline age.

Another limitation of this study was that the patients with and without fenestrations represented two distinct populations and not a single population before and after fenestration closure. Small sample size and no prior similar data comparing Fontan patients with and without fenestration also were limiting factors. The difference in baseline ages between the groups also was a limitation of this study.

\section{Conclusion}

This study demonstrated that blood flow distribution, regional oxygen extraction, and exercise time did not differ between the Fontan patients with and without fenestration during rest or exercise. A paucity of data still remains with regard to the long-term risks and benefits of fenestration, although this study has added to the data demonstrating that routine fenestration closure is necessary.

\section{References}

1. Airan B, Sharma R, Choudhary SK, Mohanty SR, Bhan A, Chowdhari UK, Juneja R, Kothari SS, Saxena A, Venugopal P (2000) Univentricular repair: is routine fenestration justified? Ann Thorac Surg 69:19001906

2. Argiento $P$, Chesler N, Mule M, D'Alto M, Bossone E, Unger P, Naeije R (2010) Exercise stress echocardiography for the study of the pulmonary circulation. Eur Respir J 35:1273-1278

3. Atz AM, Travison TG, McCrindle BW, Mahony L, Quartermain M, Williams RV, Breitbart RE, Lu M, Radojewski E, Margossian R, Covitz W, Gersony WM (2011) Late status of Fontan patients with persistent surgical fenestration. J Am Coll Cardiol 57:2437-2443

4. Bidart CM, Abbas AE, Parish JM, Chaliki HP, Moreno CA, Lester SJ (2007) The noninvasive evaluation of exercise-induced changes in pulmonary artery pressure and pulmonary vascular resistance. J Am Soc Echocardiogr 20:270-275 
5. Brassard P, Poirier P, Martin J, Noel M, Nadreau E, Houde C, Cloutier A, Perron J, Jobin J (2006) Impact of exercise training on muscle function and ergoreflex in Fontan patients: a pilot study. Int J Cardiol 107:85-94

6. Bridges ND, Lock JE, Castaneda AR (1990) Baffle fenestration with subsequent transcatheter closure: modification of the Fontan operation for patients at increased risk. Circulation 82:1681-1689

7. Bridges ND, Mayer JE Jr, Lock JE, Jonas RA, Hanley FL, Keane JF, Perry SB, Castaneda AR (1992) Effect of baffle fenestration on outcome of the modified Fontan operation. Circulation 86:1762-1769

8. Chua TP, Iserin L, Somerville J, Coats AJ (1997) Effects of chronic hypoxemia on chemosensitivity in patients with univentricular heart. J Am Coll Cardiol 30:1827-1834

9. Danduran MJ, Dixon JE, Rao RP (2012) Near-infrared spectroscopy describes physiologic payback associated with excess postexercise oxygen consumption in healthy controls and children with complex congenital heart disease. Pediatr Cardiol 33:95-102

10. Diller GP, Dimopoulos K, Okonko D, Li W, Babu-Narayan SV, Broberg CS, Johansson B, Bouzas B, Mullen MJ, Poole-Wilson PA, Francis DP, Gatzoulis MA (2005) Exercise intolerance in adult congenital heart disease: comparative severity, correlates, and prognostic implication. Circulation 112:828-835

11. Dimopoulos K, Okonko DO, Diller GP, Broberg CS, Salukhe TV, Babu-Narayan SV, Li W, Uebing A, Bayne S, Wensel R, Piepoli MF, Poole-Wilson PA, Francis DP, Gatzoulis MA (2006) Abnormal ventilatory response to exercise in adults with congenital heart disease relates to cyanosis and predicts survival. Circulation 113:2796-2802

12. Douglas PS, O'Toole ML, Hiller WD, Reichek N (1990) Different effects of prolonged exercise on the right and left ventricles. J Am Coll Cardiol 15:64-69

13. Driscoll DJ, Danielson GK, Puga FJ, Schaff HV, Heise CT, Staats BA (1986) Exercise tolerance and cardiorespiratory response to exercise after the Fontan operation for tricuspid atresia or functional single ventricle. J Am Coll Cardiol 7:1087-1094

14. Durongpisitkul K, Driscoll DJ, Mahoney DW, Wollan PC, Mottram CD, Puga FJ, Danielson GK (1997) Cardiorespiratory response to exercise after modified Fontan operation: determinants of performance. J Am Coll Cardiol 29:785-790

15. Fernandes SM, McElhinney DB, Khairy P, Graham DA, Landzberg MJ, Rhodes J (2010) Serial cardiopulmonary exercise testing in patients with previous Fontan surgery. Pediatr Cardiol 31:175-180

16. Fredriksen PM, Therrien J, Veldtman G, Warsi MA, Liu P, Siu S, Williams W, Granton J, Webb G (2001) Lung function and aerobic capacity in adult patients following modified Fontan procedure. Heart 85:295-299

17. Giardini A, Hager A, Napoleone CP, Picchio FM (2008) Natural history of exercise capacity after the Fontan operation: a longitudinal study. Ann Thorac Surg 85:818-821

18. Harrison DA, Liu P, Walters JE, Goodman JM, Siu SC, Webb GD, Williams WG, McLaughlin PR (1995) Cardiopulmonary function in adult patients late after Fontan repair. J Am Coll Cardiol 26:1016-1021

19. Imielski BR, Woods RK, Mussatto KA, Cao Y, Simpson PM, Tweddell JS (2013) Fontan fenestration closure and event-free survival. J Thorac Cardiovasc Surg 145:183-187

20. La Gerche A, Connelly KA, Mooney DJ, Maclsaac AI, Prior DL (2008) Biochemical and functional abnormalities of left and right ventricular function after ultra-endurance exercise. Heart 94:860-866

21. MacNee W (1994) Pathophysiology of cor pulmonale in chronic obstructive pulmonary disease: part two. Am J Respir Crit Care Med 150:1158-1168

22. Mahle WT, Wernovsky G, Bridges ND, Linton AB, Paridon SM (1999) Impact of early ventricular unloading on exercise performance in preadolescents with single-ventricle Fontan physiology. J Am Coll Cardiol 34:1637-1643

23. Mays WA, Border WL, Knecht SK, Gerdes YM, Pfriem H, Claytor RP, Knilans TK, Hirsch R, Mone SM, Beekman RH III (2008) Exercise capacity improves after transcatheter closure of the Fontan fenestration in children. Congenit Heart Dis 3:254-261

24. Meadows J, Lang P, Marx G, Rhodes J (2008) Fontan fenestration closure has no acute effect on exercise capacity but improves ventilatory response to exercise. J Am Coll Cardiol 52:108-113 
25. Momenah TS, Eltayb H, Oakley RE, Qethamy HA, Faraidi YA (2008) Effects of transcatheter closure of Fontan fenestration on exercise tolerance (kidecho@yahoo.com). Pediatr Cardiol 29:585-588

26. Nir A, Driscoll DJ, Mottram CD, Offord KP, Puga FJ, Schaff HV, Danielson GK (1993) Cardiorespiratory response to exercise after the Fontan operation: a serial study. J Am Coll Cardiol 22:216-220

27. Ohuchi H (2005) Cardiopulmonary response to exercise in patients with the Fontan circulation. Cardiol Young 15(Suppl 3):39-44

28. Ono M, Boethig D, Goerler H, Lange M, Westhoff-Bleck M, Breymann T (2006) Clinical outcome of patients 20 years after Fontan operation: effect of fenestration on late morbidity. Eur J Cardiothorac Surg 30:923-929

29. Owen-Reece H, Smith M, Elwell CE, Goldstone JC (1999) Near-infrared spectroscopy. Br J Anaesth 82:418426

30. Rao RP, Danduran MJ, Hoffman GM, Ghanayem NS, Berger S, Frommelt PC (2010) Cerebral hemodynamics in the presence of decreased systemic venous compliance in patients with Fontan physiology may limit anaerobic exercise capacity. Pediatr Cardiol 31:208-214

31. Rao RP, Danduran MJ, Loomba RS, Dixon JE, Hoffman GM (2012) Near-infrared spectroscopic monitoring during cardiopulmonary exercise testing detects anaerobic threshold. Pediatr Cardiol 33:791-796

32. Rosenthal M, Bush A, Deanfield J, Redington A (1995) Comparison of cardiopulmonary adaptation during exercise in children after the atriopulmonary and total cavopulmonary connection Fontan procedures. Circulation 91:372-378

33. Senzaki H, Masutani S, Kobayashi J, Kobayashi T, Sasaki N, Asano H, Kyo S, Yokote Y, Ishizawa A (2002) Ventricular afterload and ventricular work in Fontan circulation: comparison with normal two-ventricle circulation and single-ventricle circulation with Blalock-Taussig shunts. Circulation 105:2885-2892

34. Senzaki H, Masutani S, Ishido H, Taketazu M, Kobayashi T, Sasaki N, Asano H, Katogi T, Kyo S, Yokote Y (2006) Cardiac rest and reserve function in patients with Fontan circulation. J Am Coll Cardiol 47:2528-2535

35. Troutman WB, Barstow TJ, Galindo AJ, Cooper DM (1998) Abnormal dynamic cardiorespiratory responses to exercise in pediatric patients after Fontan procedure. J Am Coll Cardiol 31:668-673

36. van den Bosch AE, Roos-Hesselink JW, Van Domburg R, Bogers AJ, Simoons ML, Meijboom FJ (2004) Longterm outcome and quality of life in adult patients after the Fontan operation. Am J Cardiol 93:11411145

37. Vyas H, Driscoll DJ, Cabalka AK, Cetta F, Hagler DJ (2007) Results of transcatheter Fontan fenestration to treat protein losing enteropathy. Catheter Cardiovasc Interv 69:584-589

38. Zajac A, Tomkiewicz L, Podolec P, Tracz W, Malec E (2002) Cardiorespiratory response to exercise in children after modified Fontan operation. Scand Cardiovasc J 36:80-85 